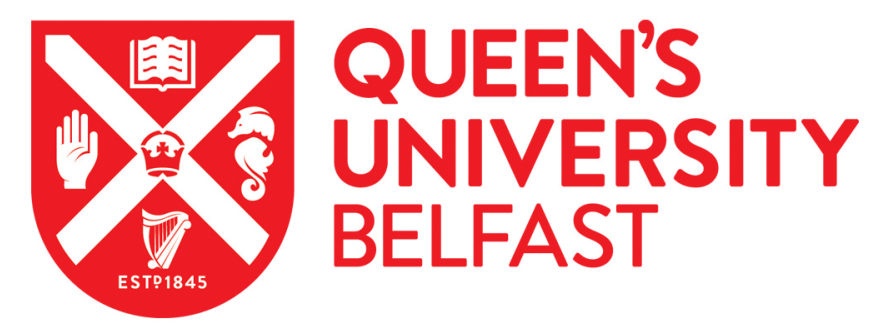

\title{
Brønsted acids in ionic liquids: How acidity depends on the liquid structure
}

\author{
McCune, J. A., He, P., Petkovic, M., Coleman, F., Estager, J., Holbrey, J. D., Seddon, K. R., \& Swadzba- \\ Kwasny, M. (2014). Brønsted acids in ionic liquids: How acidity depends on the liquid structure. Physical \\ Chemistry Chemical Physics, 16(42), 23233-23243. https://doi.org/10.1039/C4CP03217A
}

Published in:
Physical Chemistry Chemical Physics

Document Version:

Peer reviewed version

Queen's University Belfast - Research Portal:

Link to publication record in Queen's University Belfast Research Portal

\footnotetext{
General rights

Copyright for the publications made accessible via the Queen's University Belfast Research Portal is retained by the author(s) and / or other copyright owners and it is a condition of accessing these publications that users recognise and abide by the legal requirements associated with these rights.

Take down policy

The Research Portal is Queen's institutional repository that provides access to Queen's research output. Every effort has been made to ensure that content in the Research Portal does not infringe any person's rights, or applicable UK laws. If you discover content in the Research Portal that you believe breaches copyright or violates any law, please contact openaccess@qub.ac.uk.
} 


\section{ARTICLE}

Cite this: DOI: 10.1039/x0xx00000x

Received 00th January 2012

Accepted 00th January 2012

DOI: $10.1039 / \times 0 \times x 00000 x$

www.rsc.org/

\section{Brønsted acids in ionic liquids: how acidity depends on liquid structure}

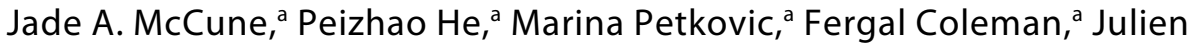 \\ Estager, ${ }^{\text {ab }}$ John D. Holbrey, ${ }^{a}$ Kenneth R. Seddon ${ }^{a}$ and Małgorzata Swadźba- \\ Kwaśny ${ }^{a *}$
}

\begin{abstract}
Gutmann Acceptor Number (AN) values have been determined for Brønsted acid-ionic liquid mixtures, over a wide compositional range. Four systems of general formula $\left[C_{2} \mathrm{mim}\right][\mathrm{A}]-\mathrm{HA}\left(\mathrm{A}^{-}=\right.$bistriflamide, $\left[\mathrm{NTf}_{2}\right]^{-}$; triflate, [OTf] ${ }^{-}$mesylate, $[\mathrm{OMs}]^{-}$; or acetate, $[\mathrm{OAc}]^{-} .\left[\mathrm{C}_{2} \mathrm{mim}\right]^{+}=1$-ethyl-3-methylimidazolium cation) were studied. A library of Brønsted acidic systems of varying acidity was constructed and the AN parameter was found to be a and convenient approach for quantifying their acidity. HOAC, HOMs and HOTf, when dissolved in ionic liquids, were found to associate with the respective anions to form hydrogen-bonded anionic clusters, $\left[\mathrm{A}(\mathrm{HA})_{x}\right]^{-}$. In contrast, $\mathrm{HNTf}_{2}$ was solubilised as a discrete, undissociated molecule. AN values were sensitive to the presence of anionic clusters; acidity could be buffered to a particular AN by binding the solubilised acid in the anionic cluster form. Overall, a simple way to manipulate and quantify the Brønsted acidity of acid-ionic liquid mixtures was demonstrated, and measured $\mathrm{AN}$ values were related to the liquid speciation.
\end{abstract}

\section{Introduction}

\section{Solutions of acids in ionic liquids}

Solutions of Brønsted acids in ionic liquids are of interest for a number of applications: as 'liquefied' pharmaceutically active drugs,${ }^{1}$ anti-fungi agents, ${ }^{2}$ components in conductive composite materials, ${ }^{3}$ and - most commonly - Brønsted acidic catalysts for a very wide range of organic reactions. ${ }^{4,5}$ At a fundamental level, these solutions are interesting as complex fluids with a dense network of hydrogen bonds.

Structural studies on systems sharing the same anion/conjugate base have shown association of complex, $\mathrm{H}$ bonded anionic clusters, $\left[\mathrm{A}(\mathrm{HA})_{x}\right]^{-6}{ }^{6}$ Organic salts and ionic liquids with halide anions have been shown to form dimeric $\left[\mathrm{X}^{\cdots} \mathrm{H}^{\cdots} \mathrm{X}^{\prime}\right]^{-}$anions when contacted with an appropriate $\mathrm{HX}$, such as $\left[\mathrm{Cl}^{\cdots} \mathrm{H}^{\cdots} \mathrm{Cl}\right]^{-}$which is stable even under reduced pressure, ${ }^{7}$ as well as other (less persistent under vacuum) oligomeric species: $\left.\left[\mathrm{Cl}(\mathrm{HCl})_{2}\right]^{-8}, \mathrm{HBr}_{2}\right]^{-},\left[\mathrm{Br}(\mathrm{HBr})_{2}\right]^{-}$and $[\mathrm{ClHBr}]^{-9}$. Solutions of triflic acid in $\left[\mathrm{C}_{2} \mathrm{mim}\right][\mathrm{OTf}]$ (see Table 1 for the list of abbreviations used in this work) were reported to contain a dense network of $\mathrm{H}$-bonds between all charged species. ${ }^{10}$ Similarly, ionic liquids formed by proton transfer between an acid and a base, with the acid in excess, have been shown to form complex anions, for example $\left[\mathrm{F}(\mathrm{HF})_{x}\right]^{-11}[\mathrm{tfa}(\mathrm{Htfa})]^{-6},{ }^{1}$ $\left[\mathrm{HSO}_{4}\left(\mathrm{H}_{2} \mathrm{SO}_{4}\right)_{x}\right]^{-5}$ and a wide range of carboxylate-carboxylic acid clusters. ${ }^{1,12,13}$ Poorly ionic mixtures of 1-methylpyrrolidine and acetic acid were shown to contain polymeric $\left[\mathrm{OAc}(\mathrm{HOAc})_{x}\right]^{-}$anions. ${ }^{13}$ Such clusters are not specific to ionic liquids environment; they were observed in aqueous solutions, ${ }^{14}$ non-polar solvents, ${ }^{15}$ and are often found in crystal structures. ${ }^{16}$

\begin{tabular}{ll}
\hline Table 1. A list of ions abbreviations used in this contribution \\
\hline cation & \\
\hline 1-ethyl-3-methylimidazolium & {$\left[\mathrm{C}_{2} \mathrm{mim}\right]^{+}$} \\
1-methylpyrrolidinium & {$[\mathrm{Hmpyr}]^{+}$} \\
\hline anion & $\mathrm{X}^{-}(\mathrm{X}=\mathrm{Cl}$ or Br) \\
\hline halide & {$[\mathrm{OAc}]^{-}$} \\
ethanoate (acetate) & {$[\mathrm{tfa}]^{-}$} \\
trifluoroethanoate (trifluoroacetate) & {$[\mathrm{OMs}]^{-}$} \\
methanesulfonate (mesylate) & {$[\mathrm{OTf}]^{-}$} \\
trifluoromethanesulfonate (triflate) & {$\left[\mathrm{NTf}_{2}\right]^{-}$} \\
bis $\{$(trifluoromethyl)sulfonyl $\}$amide (bistriflamide)
\end{tabular}

\section{The acidity of bistriflamidic acid}

Hydrogen bis $\{$ (trifluoromethyl)sulfonyl $\}$ amide, $\operatorname{HNTf}_{2}$, contains an acidic $\mathrm{N}-\mathrm{H}$ function, in contrast to the more common $\mathrm{O}-\mathrm{H}$ function found in many acids. Pure $\mathrm{HNTf}_{2}$ is a low-melting solid $\left(49-50{ }^{\circ} \mathrm{C}\right),{ }^{17}$ which crystallises in a characteristic ribbon-like structure (Figure 1$).{ }^{18}$ In the crystal structure of $\mathrm{HNTf}_{2}$, the $\mathrm{NTf}_{2}$ unit is in the trans-position, which is theoretically favourable by $2.3 \mathrm{~kJ} \mathrm{~mol}^{-1}$. ${ }^{19}$ However, in salts, $\left[\mathrm{NTf}_{2}\right]^{-}$can crystallise in either a cis-or trans-conformation (depending on the cation), and in the liquid phase (solutions or ionic liquids) it tends to assume both cis- and transconformations in a dynamic equilibrium. ${ }^{20}$ 


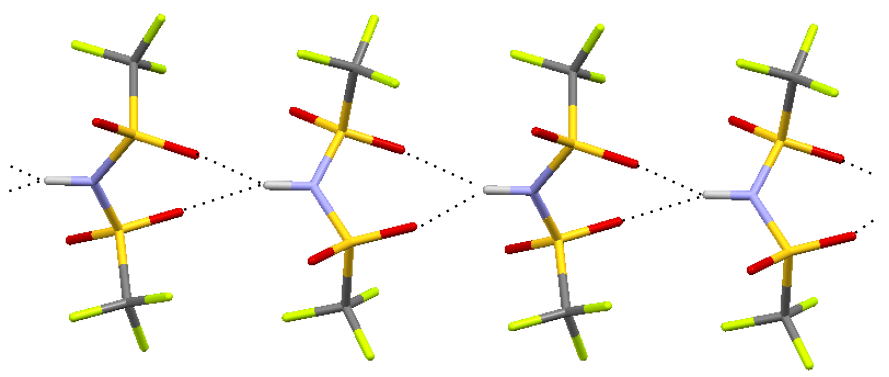

Figure 1. Crystal structure of $\mathrm{HNTf}_{2}$, showing strands of $\mathrm{H}$-bonded $\mathrm{HNTf}_{2}$ units ( $\mathrm{H}$-bonds - turquoise; C - grey, $\mathrm{S}$ - yellow, $\mathrm{O}$ - red, $\mathrm{F}$ - lime, $\mathrm{N}$ - purple and $\mathrm{H}$ white). ${ }^{18}$

$\mathrm{HNTf}_{2}$ is generally recognised to be a very strong acid. In the gas phase, $\mathrm{HNTf}_{2}$ was found to be a stronger acid than HOTf. $^{21}$ In glacial acetic acid solution, HOTf was measured to be stronger than $\operatorname{HNTf}_{2}\left(\mathrm{p} K_{\mathrm{a}}=4.2\right.$ vs. 7.8$),{ }^{17}$ but both acids were classified as very strong. In contrast, when equimolar amounts of water and $\mathrm{HNTf}_{2}$ were dissolved in a noncoordinating solvent, such as $\mathrm{CCl}_{4}$ or benzene, $\mathrm{HNTf}_{2}$ did not protonate water, behaving like a weak acid. ${ }^{15}$ This was in stark contrast to other acids, such as HOTf or $\mathrm{H}_{2} \mathrm{SO}_{4}$. Furthermore, $\mathrm{HNTf}_{2}$ dissolved in anhydrous non-polar solvents did not form $\mathrm{H}$-bonded clusters, $\left[\mathrm{HNTf}_{2}\right]_{x}$, but was solubilised in a molecular form (again, in contrast to HOTf). Stoyanov et al. ${ }^{15}$ argued that $\left[\mathrm{NTf}_{2}\right]^{-}$is such a very weak base/hydrogen bond acceptor, that it is energetically more favourable for $\mathrm{HNTf}_{2}$ to be solvated by solvent molecules, than to form the cluster, $\left[\mathrm{NTf}_{2}\left(\mathrm{HNTf}_{2}\right)\right]^{-}$.

\section{Acidity in protic ionic liquids}

Many techniques have been used to measure the acidity of ionic liquids, and equally, many different scales have been used to express the results. Approach used routinely for aqueous solutions pose technical difficulties in non-aqueous media. ${ }^{22}$ Establishing $\mathrm{pH}$ or $\mathrm{p} K_{\mathrm{a}}$ in ionic liquid media is possible, albeit challenging, as it requires specialised equipment. ${ }^{23}$ Hammett acidities reported vary widely depending on the measurement procedure used, ${ }^{24,25}$ and the measurements are extremely sensitive to impurities, as they rely on UV-VIS probes. ${ }^{26} \mathrm{~A}$ range of methodologies, associated difficulties, and best recommended practice have been expertly discussed by Johnson and co-workers. ${ }^{24,25}$ A noteworthy addition to this strand of research is the use of an NMR probe to measure Hammett acidity, very recently introduced in ionic liquids by Welton and co-workers. ${ }^{27}$

In this work, a Guttmann Acceptor Number $(A N)^{28}$ approach has been employed, which benefits from straightforward NMR-based methodology, and in the literature good correlations are found for measurements performed independently by different groups. Finally, the AN scale is a quantitative measure of acidity applicable to both Lewis and Brønsted acids.

AN values are determined by ${ }^{31} \mathrm{P}$ NMR spectroscopy, making use of small quantities of the weakly basic ${ }^{31} \mathrm{P}$ NMR probe molecule, triethylphosphine oxide (tepo), which is dissolved in the medium under investigation. Changes in the ${ }^{31} \mathrm{P}$ NMR chemical shift are induced through formation of acidbase adducts with Lewis acids, or partial protonation by Brønsted acids (Figure 2).

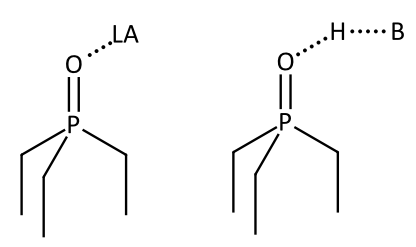

Figure 2. Interactions of the spectroscopic probe, triethylphosphine oxide (tepo) with a Lewis acid (LA), left, and with a Brønsted acid (HB), right.

AN measurements were used to study Lewis acidity of chlorometallate ionic liquids, ${ }^{29}$ and to investigate a wide range of 'typical' ionic liquids.

Acidity, expressed on both Hammett $^{31}$ and Guttmann ${ }^{5}$ scales, was demonstrated to be among key factors affecting catalytic performance of Brønsted acidic ionic liquids.

\section{Aim of this work}

The principal objective was to study the acidity of acid-ionic liquid mixtures as a function of their composition, investigating examples of both weak and strong acids. It was aimed to understand the relationship between the acidity of such systems, i.e. AN values, and their speciation, i.e. the presence of anionic H-bonded clusters. Quantification of acidity for different acids, at a range of compositions, will lead to establishing a library of systems with a fine-tuned acidity, in analogy to the library of Lewis acidic ionic liquids, previously established by our group. ${ }^{32}$ This approach should provide more insight into the selection of acidic ionic liquid systems as homogenous catalysts.

\section{Experimental}

\section{Materials}

Unless otherwise stated, all materials were purchased from Sigma-Aldrich and used as received. Triethylphosphine oxide was purchased from Sigma-Aldrich, opened and stored in a nitrogen-filled glovebox (MBraun LabMaster dp; <0.1 ppm $\mathrm{O}_{2}$ and $\mathrm{H}_{2} \mathrm{O}$ ). Ethyl trifluoromethanesulfonate, 99\%, was purchased in glass ampoules packed under argon. $\left[\mathrm{C}_{2} \mathrm{mim}\right] \mathrm{Br}$ was prepared by alkylation of 1-methylimidazole with bromoethane according to a standard literature procedure.

\section{Syntheses}

In all cases, these are improved modifications of known synthetic procedures. ${ }^{33-36}$

HNTf $_{2}{ }^{33} \mathrm{Li}\left[\mathrm{NTf}_{2}\right]$ (1.00 mol eq.) and sulfuric acid, (3.00 mol eq.,) were placed in a cylindrical Kugelrohr flask and fixed to a Kugelrohr distillation apparatus. High vacuum was applied and the temperature of the oven was elevated slowly until the first signs of sublimation were observed $\left(\sim 50^{\circ} \mathrm{C}\right)$. After the sublimation, white crystals were gathered in the collector flask, which was cooled with ice throughout the experiment. The hygroscopic, fuming sublimate was melted using a heat-gun and very quickly transferred into a bottle with a sealable, corrosion-resistant cap. The product was obtained as a white, low-melting solid, typically in $75-80 \%$ yield.

$\left[\mathbf{C}_{2} \mathbf{m i m}\right]\left[\mathbf{N T f}_{2}\right]^{34}$ In a typical synthesis, concentrated aqueous solutions of $\left[\mathrm{C}_{2} \mathrm{mim}\right] \mathrm{Br}(1.0 \mathrm{~mol} \mathrm{eq})$ and $\operatorname{LiNTf}_{2}(1.2 \mathrm{~mol} \mathrm{eq})$ were poured into a round-bottomed flask equipped with a stirring bar. The flask was closed with a stopper and the mixture was stirred vigorously (30 $\mathrm{min})$. Subsequently, the top (aqueous) layer was decanted, and the bottom (ionic liquid) 
layer was washed three times with an aqueous solution of LiNTf $_{2}$ and ten times with deionised water. Remaining solvents were removed using a rotary evaporator $\left(80^{\circ} \mathrm{C}, 1 \mathrm{~h}\right)$ and then high vacuum $\left(80^{\circ} \mathrm{C}\right.$, overnight, $\left.10^{-2} \mathrm{mbar}\right)$. The purity and structure of the product were confirmed using ${ }^{1} \mathrm{H},{ }^{13} \mathrm{C}$, and ${ }^{19} \mathrm{~F}$ NMR spectroscopy. Efficiency of anion exchange was confirmed by elemental analysis $(\mathrm{Li}<0.005$ wt \%; $\mathrm{Br}=0.13 \mathrm{wt} \%$ ).

$\left[\mathbf{C}_{2} \text { mim][OTf }\right]^{34}$ 1-Methylimidazole (1.0 mol eq) was poured into a two-necked round-bottomed flask equipped with a stirring bar, an equal volume of dichloromethane was added to the same flask, and the solution was stirred vigorously in an ice bath $\left(0^{\circ} \mathrm{C}\right)$ until cooled. An ampoule of ethyl trifluoromethanesulfonate $(1.1 \mathrm{~mol} \mathrm{eq})$ was opened in a glovebox and the content was transferred immediately into a pressure-equalising dropping funnel, which was closed with a stopper, taken out of the glovebox, and mounted on the flask containing the cooled solution. The whole setup was connected to a Schlenk line and purged with argon. Ethyl trifluoromethanesulfonate was added dropwise into the vigorously stirred reaction mixture (ca. $20 \mathrm{~min}$ ). Afterwards, the reaction was carried out overnight, gradually reaching room temperature. The product (room temperature ionic liquid) was washed four times with ethyl acetate, and the remaining solvent was removed using the rotary evaporator $\left(1 \mathrm{~h}, 40^{\circ} \mathrm{C}\right)$. Finally, the synthesised ionic liquid was dried under high vacuum $\left(70{ }^{\circ} \mathrm{C}\right.$, overnight). The purity and structure of the product were confirmed using ${ }^{1} \mathrm{H},{ }^{13} \mathrm{C}$, and ${ }^{19} \mathrm{~F}$ NMR spectroscopy.

$\left[\mathbf{C}_{2} \mathbf{m i m}\right][\mathbf{O M s}]^{35}$ 1-Methylimidazole $(1.0 \mathrm{~mol}$ eq) was poured into a two-necked round-bottomed flask equipped with a stirring bar and stirred vigorously in an oil bath $\left(40^{\circ} \mathrm{C}\right)$. Ethyl methanesulfonate $(1.2 \mathrm{~mol}$ eq) was transferred into a pressureequalising dropping funnel, which was closed with a stopper and mounted on the round-bottomed flask; the whole setup was connected to a Schlenk line and purged with argon. Ethyl methanesulfonate was added dropwise into the vigorously stirred reaction mixture $(c a .20 \mathrm{~min})$. After the reaction (overnight, $40^{\circ} \mathrm{C}$ ), the product (room temperature ionic liquid) was washed four times with ethyl acetate, and the remaining solvent was removed using the rotary evaporator $\left(1 \mathrm{~h}, 40^{\circ} \mathrm{C}\right)$. Finally, the synthesised ionic liquid was dried under high vacuum $\left(70^{\circ} \mathrm{C}\right.$, overnight). The purity and structure of the product were confirmed using ${ }^{1} \mathrm{H}$ and ${ }^{13} \mathrm{C}$ NMR spectroscopy.

$\left[\mathbf{C}_{2} \mathbf{m i m}\right][\mathbf{O A c}]^{36}\left[\mathrm{C}_{2} \mathrm{mim}\right]\left[\mathrm{HSO}_{4}\right](1.0 \mathrm{~mol}$ eq. $)$ was poured into a round-bottomed flask equipped with a stirring bar and dissolved in hot deionised water $\left(95-100{ }^{\circ} \mathrm{C}\right)$. Strontium hydroxide octahydrate ( $1.2 \mathrm{~mol}$ eq.) was weighed into a conical flask and dissolved in hot deionised water $\left(95-100{ }^{\circ} \mathrm{C}\right)$. The $\left[\mathrm{C}_{2} \mathrm{mim}\right]\left[\mathrm{HSO}_{4}\right]$ solution was quantitatively transferred to the same conical flask, and the cloudy mixture was stirred vigorously $\left(27^{\circ} \mathrm{C}, 30 \mathrm{~min}\right)$ before being allowed to cool. The white precipitate (strontium hydrogensulfate) was removed via double filtration under reduced pressure (P3 glass sintered funnel with a $0.5 \mathrm{~cm}$ silica gel layer), washed with deionised water $\left(\mathrm{ca} .20{ }^{\circ} \mathrm{C}\right)$ and discarded. The colourless solution of $\left[\mathrm{C}_{2} \mathrm{mim}\right][\mathrm{OH}]$ was neutralised to the expected $\mathrm{pH}$ of $\left[\mathrm{C}_{2} \mathrm{mim}\right][\mathrm{OAc}]$ aqueous solution, $\mathrm{pH}=8.4$, by the addition of acetic acid (1.0 mol eq.). Water was removed using a rotary evaporator $\left(40^{\circ} \mathrm{C}, 1 \mathrm{~h}\right)$. To the crude ionic liquid, an equal volume of dichloromethane/acetonitrile mixture (1:2 vol ratio) was added, resulting in a small amount of fine white precipitate, which was again removed by filtration under reduced pressure. Finally, solvent was removed using the rotary evaporator $(1 \mathrm{~h}$, $40^{\circ} \mathrm{C}$ ), and then the ionic liquid was dried under high vacuum $\left(50{ }^{\circ} \mathrm{C}, 2\right.$ days). The purity and structure of the product were confirmed using ${ }^{1} \mathrm{H}$ and ${ }^{13} \mathrm{C}$ NMR spectroscopy.

[C $\left.\mathbf{C}_{2} \mathbf{m i m}\right][\mathbf{A}]-\mathbf{H A}$ In a typical experiment, ionic liquid (ca. $3 \mathrm{~g}$ ) was weighed out into a sample vial equipped with a stirring bar. An appropriate amount of acid was weighed in the fumehood, directly into the sample vial containing the ionic liquid, using a Pasteur pipette (or a spatula for $\mathrm{HNTf}_{2}$ ), to achieve the desired ratio of acid to ionic liquid. Actual masses of both reactants were recorded. The vial was closed with a plastic cap and stirred vigorously (ambient temperature, $c a .30 \mathrm{~min}$ ) to ensure homogeneity. Argon was bubbled through this solution (ambient temperature, $c a .30 \mathrm{~min}$ ), which was subsequently placed in the glovebox.

\section{Analytical methods}

AN MEASUREMENTS. Sample preparation was carried out in a dry, nitrogen-filled glovebox. In a typical experiment, a sample (ca. $1 \mathrm{~g}$ ) of each composition was weighed into a sample vial $\left(10 \mathrm{~cm}^{3}\right)$ equipped with a PTFE-coated magnetic stirring bar. The vial was left on the balance, and a small, accurately measured, amount of triethylphosphine oxide (tepo) was added (1-5 mol \% per mol of the $\left[\mathrm{C}_{2} \mathrm{mim}\right]^{+}$cation). The sample vial was then closed with a plastic cap and the mixture was stirred overnight to ensure complete dissolution of tepo. Subsequently, the liquid was loaded into an NMR tube $(5 \mathrm{~mm}$, borosilicate glass), containing a sealed capillary with $d_{6}$-dimethylsulfoxide (as an external lock). The tube was closed with a standard cap, sealed with parafilm, and removed from the glovebox immediately prior to measurement. For each ionic liquid-acid mixture studied, three samples with different small quantities of tepo were prepared, to allow extrapolation of the ${ }^{31} \mathrm{P}$ NMR chemical shift value to infinite dilution, $\delta_{\text {inf. }}$.

${ }^{31} \mathrm{P}$ NMR spectra were acquired at $121.452 \mathrm{MHz}$ using a Bruker DRX 300 spectrometer. Phosphoric acid, 85\% solution in water, was used as an external reference. All samples were measured at $27^{\circ} \mathrm{C}$. Moreover, the three solutions of tepo in hexane ( $c a .5,10$ and $15 \mathrm{~mol} \%$ ) were prepared, and then measured at $27{ }^{\circ} \mathrm{C}$. For each ionic liquid, the ${ }^{31} \mathrm{P}$ NMR chemical shift for the infinite dilution of tepo, $\delta_{\text {inf, }}$ was determined by extrapolation from the ${ }^{31} \mathrm{P}$ NMR chemical shifts measured at different tepo concentrations. The chemical shift of tepo in hexane, extrapolated to infinite dilution, $\delta_{\text {inf hex }}$, was used as a reference $\left(\delta_{\text {inf hex }}=0 \mathrm{ppm}\right)$. The AN values for all samples were calculated from the following formula: $\mathrm{AN}=$ $2.348 \cdot \delta_{\text {inf. }}{ }^{28}$

${ }^{1}$ H AND ${ }^{13}$ C NMR SPECTROSCOPY In the glovebox, neat ionic liquids were loaded into NMR tubes $(5 \mathrm{~mm}$, borosilicate glass) containing sealed capillaries with $d_{6}$-dimethylsulfoxide (as an external lock). The tubes were closed with a standard cap, sealed with parafilm, and removed from the glovebox immediately prior to measurement. All spectra were measured at $27^{\circ} \mathrm{C}$, using a Bruker DRX 300 spectrometer.

\section{Results and Discussion}

\section{Experimental plan}

CHOICE OF ACIDS Four ionic liquid-acid systems of a general formula $\left[\mathrm{C}_{2} \mathrm{mim}\right][\mathrm{A}]-\mathrm{HA}\left(\mathrm{A}=\mathrm{NTf}_{2}, \mathrm{OTf}, \mathrm{OMs}\right.$, or OAc $)$ were prepared, with varying molar ratios of acids, $\chi_{\text {HA }}$. All samples were mobile liquids, from colourless to pale yellow. For the $\left[\mathrm{C}_{2} \mathrm{mim}\right]\left[\mathrm{NTf}_{2}\right]-\mathrm{HNTf}_{2}$ system, homogenous solutions were formed for $\chi_{\mathrm{HNTf2}} \leq 0.80$; for higher acid concentrations, the mixture was a biphasic liquid at elevated temperatures (fine 
droplets suspended in bulk liquid), and the whole sample solidified over several minutes upon cooling, starting from the suspended phase.

The acids were chosen to represent a wide acidity spectrum. Acetic acid is a weak carboxylic acid, known to form strong anionic clusters. HOMs and HOTf are very strong sulfonic acids, commonly used in catalysis. The only structural difference between them is perfluorination of the methyl group in the latter case, which increases the acidity of HOTf with respect to HOMs. The interesting character of the $\mathrm{HNTf}_{2}$ system has been discussed above; furthermore, $\left[\mathrm{NTf}_{2}\right]^{-}$-based ionic liquids are hydrophobic, hence may be of particular interest for catalytic applications.

Each system shared the same anion and conjugate base of the acid; for two different bases in the system, the proton would associate with the stronger base, as already reported in the literature. ${ }^{26}$ The same publication demonstrated that cations have negligible influence on the acidity.

DeFinition OF MOLAR RATIO OF ACID, $\chi_{\mathrm{HA}}$. Previous studies on $\mathrm{H}$-bonded clusters in ionic liquids have focussed on proton transfer systems, where their composition was expressed as a molar ratio of acid, $\chi_{\mathrm{HA}}$ (Eqn 1$)$.

$$
\begin{aligned}
1 / 2 \mathrm{HA}+\mathrm{B} & \leftrightarrow 1 / 2\left[\mathrm{HB}_{2}\right][\mathrm{A}] & \chi_{\mathrm{HA}}=0.33 \\
\mathrm{HA}+\mathrm{B} & \leftrightarrow[\mathrm{HB}][\mathrm{A}] & \chi_{\mathrm{HA}}=0.50 \\
2 \mathrm{HA}+\mathrm{B} & \leftrightarrow[\mathrm{HB}][\mathrm{A}(\mathrm{HA})] & \chi_{\mathrm{HA}}=0.67 \\
3 \mathrm{HA}+\mathrm{B} & \leftrightarrow[\mathrm{HB}]\left[\mathrm{A}(\mathrm{HA})_{2}\right] & \chi_{\mathrm{HA}}=0.75
\end{aligned}
$$

In this work, the starting point is an ionic liquid, $\left[\mathrm{C}_{2} \mathrm{mim}\right][\mathrm{A}]$, which is reacted with an acid, HA. To facilitate comparison with previous contributions, we perform a Gedanken experiment assuming that the ionic liquid was prepared by addition of an acid to a carbene $\left(\mathrm{p} K_{\mathrm{a} 2 \mathrm{O}}=c a .27\right),{ }^{37}$ as shown in Eqn 2.<smiles></smiles>$$
\chi_{\mathrm{HA}}=0.50(2 \mathrm{a})
$$<smiles>CCN1[C]N(C)C=C1</smiles><smiles>[C+]1CCCC1</smiles><smiles>Cn1cc[n+](C)c1</smiles>

$\chi_{\mathrm{HA}}=0.67$

Following this logic, the composition of neat ionic liquid, $\left[\mathrm{C}_{2} \mathrm{mim}\right][\mathrm{A}]$, is described by $\chi_{\mathrm{HA}}=0.50$, solutions of acids are characterised by $0.50<\chi_{\mathrm{HA}}<1.00$, and neat acid as $\chi_{\mathrm{HA}}=1.00$.

\section{The acidity of acid-ionic liquid mixtures}

MeAsurements AND OBSERVED TRENDS The spectroscopic probe, tepo, was used in very low concentrations to minimise the interference with equilibria in studied systems. Recorded ${ }^{31} \mathrm{P}$ NMR signals of the protonated probe were found to be slightly concentration-dependent, as exemplified in Figure 3. To eliminate this factor, the ${ }^{31} \mathrm{P}$ NMR shifts were extrapolated to infinite dilution of tepo, $\delta_{\text {inf }}$, using linear regression. The $\delta_{\text {inf }}$ values were then used to calculate AN (Table 2).

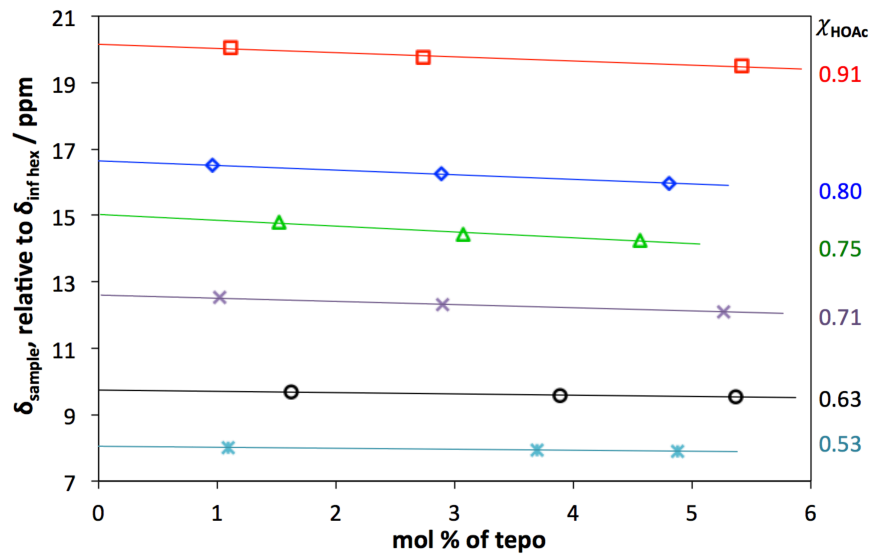

Figure 3. Experimental ${ }^{31} \mathrm{P}$ NMR chemical shifts for tepo as a function of tepo concentration in selected [ $\left.\mathrm{C}_{2} \mathrm{mim}\right][\mathrm{OAc}]-\mathrm{HOAc}$ compositions, expressed as $\chi_{\text {HOAc }}$. Experimental data were extrapolated to infinite dilution, $\delta_{\text {inf }} / \mathrm{ppm}$, using linear regression.

Table 2. AN values for different compositions for four ionic liquid-acid systems of a general formula $\left[\mathrm{C}_{2} \mathrm{mim}\right][\mathrm{A}]-\mathrm{HA}$, where $\chi_{\mathrm{HA}}$ is the molar ratio of acid used theoretically in Eqn 2

\begin{tabular}{cccccccc}
\multicolumn{2}{c}{$\mathbf{A}=\mathbf{N T f}_{\mathbf{2}}$} & \multicolumn{2}{c}{$\mathbf{A}=\mathbf{O T f}$} & \multicolumn{2}{c}{$\mathbf{A}=\mathbf{O M s}$} & \multicolumn{2}{c}{$\mathbf{A}=\mathbf{O A c}$} \\
$\boldsymbol{\chi}_{\mathbf{H A}}$ & \multicolumn{1}{c}{$\mathbf{A N}$} & \multicolumn{1}{c}{$\boldsymbol{\chi}_{\mathbf{H A}}$} & \multicolumn{1}{c}{$\mathbf{A N}$} & \multicolumn{1}{c}{$\chi_{\mathbf{H A}}$} & $\mathbf{A N}$ & $\chi_{\mathbf{H A}}$ & $\mathbf{A N}$ \\
\hline 0.50 & 28.3 & 0.50 & 33.4 & 0.50 & 25.4 & 0.50 & 16.9 \\
0.51 & 124.4 & 0.51 & 118.6 & 0.51 & 83.4 & 0.53 & 18.9 \\
0.51 & 125.5 & 0.51 & 118.7 & 0.51 & 86.6 & 0.56 & 19.5 \\
0.52 & 123.5 & 0.52 & 118.0 & 0.52 & 89.5 & 0.59 & 19.9 \\
0.53 & 124.9 & 0.53 & 119.4 & 0.56 & 95.3 & 0.60 & 21.5 \\
0.56 & 123.3 & 0.54 & 117.6 & 0.57 & 95.8 & 0.61 & 21.6 \\
0.59 & 124.1 & 0.56 & 117.6 & 0.59 & 96.1 & 0.63 & 22.9 \\
0.60 & 124.9 & 0.56 & 117.6 & 0.60 & 96.0 & 0.64 & 21.0 \\
0.60 & 123.3 & 0.60 & 117.2 & 0.60 & 94.9 & 0.66 & 22.6 \\
0.62 & 124.3 & 0.60 & 117.2 & 0.60 & 96.3 & 0.69 & 26.2 \\
0.62 & 124.5 & 0.64 & 117.3 & 0.61 & 95.9 & 0.71 & 29.6 \\
0.64 & 123.5 & 0.64 & 117.3 & 0.64 & 95.3 & 0.75 & 35.3 \\
0.64 & 124.3 & 0.67 & 118.9 & 0.64 & 95.9 & 0.80 & 39.1 \\
0.66 & 124.8 & 0.67 & 118.8 & 0.65 & 96.1 & 0.91 & 47.3 \\
0.67 & 123.3 & 0.71 & 121.9 & 0.67 & 98.3 & 1.00 & 52.9 \\
0.71 & 123.5 & 0.75 & 123.2 & 0.71 & 105.5 & & \\
0.71 & 125.1 & 0.80 & 125.3 & 0.71 & 105.8 & & \\
0.75 & 123.9 & 0.86 & 127.7 & 0.75 & 111.0 & & \\
0.77 & 124.0 & 0.92 & 129.3 & 0.78 & 115.4 & & \\
0.80 & 124.4 & 1.00 & 129.1 & 0.80 & 116.5 & & \\
0.83 & - & & & 0.86 & 121.2 & & \\
0.86 & - & & & 0.92 & 124.5 & & \\
1.00 & - & & & 1.00 & 126.1 & & \\
\hline & & & & & & &
\end{tabular}

${ }^{\mathrm{a}}$ Extrapolated value; see further discussion in the text

To facilitate meaningful analysis of the data, AN values for the four investigated systems were plotted against the composition, $\chi_{\mathrm{HA}}$ (Figure 4 ). 


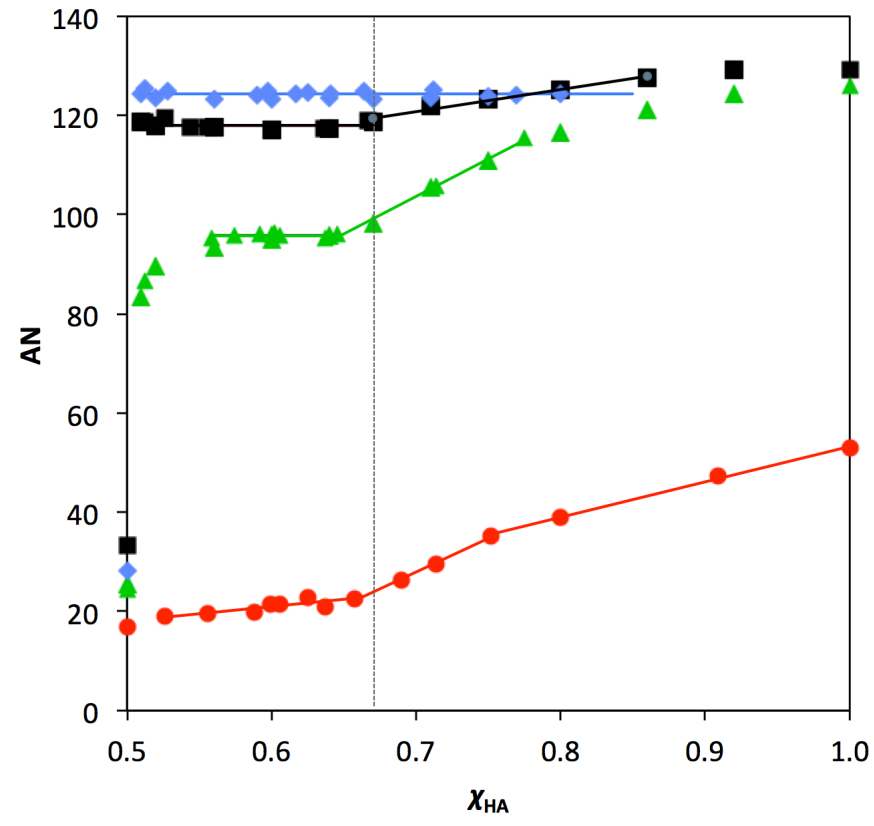

Figure 4. AN values in four systems of a general formula $\left[C_{2}\right.$ mim] $[A]-H A$, where $A=\operatorname{OAc}(\bullet)$, OMs $(\Delta)$, OTf $(\square)$ and $\mathrm{NTf}_{2}(\bullet)$. The composition is given in mol ratio of acid to 1-ethyl-3-methylimidazole carbene, $\chi_{\text {HA }}$. The lines are fitted by linear regression. Dashed line at $\chi_{\mathrm{HA}}=0.67$ is a guidline for the eye.

Neat ionic liquids all have low acidity; measured values are in close agreement with those reported in the literature. ${ }^{30}$ As anticipated, in all cases AN values increase with increasing acid concentration. In no case is the increase in AN value directly proportional to $\chi_{\mathrm{HA}}$.

In the acetate system (Figure 4, $\bullet$ ), upon the addition of acid to the neat ionic liquid, there is a slow, linear increase in $\mathrm{AN}$ up to $\chi_{\mathrm{OAc}}=0.67$; the acidity is buffered to a nearly constant AN value by the formation of the [OAc(HOAc)] complex, which is held together by strong hydrogen bonds. Moving towards higher acid content, AN values increase more rapidly up to $\chi_{\mathrm{OAc}}=0.75$, as dimers are gradually replaced by $\left[(\mathrm{OAc})(\mathrm{HOAc})_{2}\right]^{-}$. Finally, between $\chi_{\mathrm{OAc}}=0.75$ and 1.00 , AN increases linearly; it can be envisaged that the structure of the liquid gradually shifts from that of an ionic liquid to that of a pure acid. Fitted linear regressions are given in Eqn 2.

$$
\begin{aligned}
& \mathrm{AN}=33.999 \cdot \chi_{\mathrm{HOAc}}+0.521 ; R^{2}=0.856 ; 0.50<\chi_{\mathrm{HOAc}}<0.67(2 \mathrm{a}) \\
& \mathrm{AN}=135.78 \cdot \chi_{\mathrm{HOAc}}-67.091 ; R^{2}=0.995 ; 0.67 \leq \chi_{\mathrm{HOAc}} \leq 0.75(2 \mathrm{~b}) \\
& \mathrm{AN}=71.337 \cdot \chi_{\mathrm{HOAc}}-18.075 ; R^{2}=0.997 ; 0.75 \leq \chi_{\mathrm{HOAc}}<1.00(2 \mathrm{c})
\end{aligned}
$$

This interpretation is in line with previous structural studies on similar systems, in particular with work on 1-methylpyrrolidine-acetic acid mixtures by MacFarlane and co-workers. ${ }^{13}$

In the mesylate system (Figure $4, \Delta$ ), addition of a small amount of acid results in a rapid increase in acidity, which then remains constant $(\mathrm{AN}=95.8 \pm 0.5)$ for $0.52>\chi_{\mathrm{HOMs}}>0.65$. Between $\chi_{\mathrm{HOMs}}=0.65$ and 0.78 , $\mathrm{AN}$ increases linearly, following Eqn 3, and subsequently the behaviour deviates from linear, approaching the acidity of pure acid.

$\mathrm{AN}=144.69 \cdot \chi_{\mathrm{HOMs}}+2.6626 ; R^{2}=0.993 ; 0.65 \leq \chi_{\mathrm{HOMs}} \leq 0.78(3)$

In the triflate system (Figure 4, a), even the smallest quantity of acid caused an immense increase in acidity, which was buffered at $\mathrm{AN}=118 \pm 0.8$ for $0.50>\chi_{\mathrm{HOTf}} \geq 0.67$. This can be rationalised by the formation of [OTf(HOTf)], which had been found in both ionic liquids ${ }^{10}$ and in molecular solvents. ${ }^{15}$ Afterwards, AN values increased linearly up to $\chi_{\text {HOTf }}=0.86$ (Eqn 4), suggesting formation of weakly-bound oligonuclear clusters, ${ }^{10}$ and subsequently, deviating from linearity, they reached the acidity of pure acid.

$\mathrm{AN}=49.142 \cdot \chi_{\mathrm{HOTf}}+86.266 ; R^{2}=0.974 ; 0.67 \leq \chi_{\mathrm{HOTf}} \leq 0.86$

How can these trends be justified in terms of dynamic equilibria? In the region of $0.50<\chi_{\mathrm{HA}}<0.67$, buffering to a constant AN value was observed. This buffering occurs according to Eqn 5, for the case where $x=0$ to 1 , and the equilibrium is strongly shifted to the right.

$\left[\mathrm{A}(\mathrm{HA})_{x}\right]^{-}+\mathrm{HA} \rightleftarrows\left[\mathrm{A}(\mathrm{HA})_{x+1}\right] ; x=0$ to 6

Interestingly, although the acidities of neat HOTf and HOMs are quite similar $\left(\triangle \mathrm{AN}=\mathrm{AN}_{\mathrm{HOTf}}-\mathrm{AN}_{\mathrm{HOMs}}=3\right)$, the mesylate system is buffered to a much lower acidity $(\triangle \mathrm{AN}>20)$, as shown in Figure 4. Since [OMs] is a better $\mathrm{H}$-bond acceptor than [OTf] $]^{-}$, protons are more strongly bound within $[\mathrm{OMs}(\mathrm{HOMs})]^{-}$clusters, which in turn leads to lower $\mathrm{AN}$ values.

For $0.67<\chi_{\mathrm{HA}}<1.00$, the structure of the liquid changes from acid dissolved in ionic liquid, to ionic liquid dissolved in acid. Acetic acid is a very structured medium, with a strong network of $\mathrm{H}$-bonds. It is visible that acetates form [A(HA) ] (up to $\left.\chi_{\mathrm{HA}}=0.67\right)$ then $\left[\mathrm{A}(\mathrm{HA})_{2}\right]^{-}$(up to $\left.\chi_{\mathrm{HA}}=0.75\right)$, and then acid becomes the continuous medium (Eqn 5 is shifted to the left for $\left.\chi_{\mathrm{HA}}>0.75\right) .{ }^{13,38} \mathrm{HOMs}$ and HOTf are less structured, as their conjugate bases are weaker H-bond acceptors. Therefore, the 'ionic' structure prevails longer: up to $\chi_{\mathrm{HOMs}} \cong 0.78$ in the mesylate system, and up to $\chi_{\text {HOTf }} \cong 0.85$ in the triflate system. Past these $\chi_{\mathrm{HA}}$ values, Eqn 5 is shifted to the left.

In the bistriflamide system (Figure $4, \bullet$ ), as in the triflate one, the addition of a small amount of acid leads to a spike in acidity, up to a very high level of $\mathrm{AN}=124.3 \pm 0.8$. However, in contrast to other systems, this value remains constant throughout the measurable composition range $0.05<\chi_{\mathrm{NTf} 2} \leq$ 0.80 . This suggests that there are no clusters formed in this range, and that $\mathrm{HNTf}_{2}$ is dissolved in its molecular form, as found in the work on acid solutions in non-polar solvents by Stoyanov et al. ${ }^{15}$ For $0.80<\chi_{\mathrm{NTf2}}<1.00$, the mixtures formed biphasic liquids at elevated temperature and solidified readily (forming solid with small amount of encapsulated liquid) when cooled to ambient.

IMPLICATIONS. Solutions of HOTf or $\mathrm{HNTf}_{2}$ in analogous ionic liquids are both extremely acidic, with the $\mathrm{HNTf}_{2}$ system being slightly more so. This is in agreement with the suggestion of Johnson and co-workers, that gas-phase acidities of neat acids might be more indicative of acidities of ionic liquid solutions than the $\mathrm{p} K_{\mathrm{a}}$ values of the corresponding acids in water. ${ }^{24}$

Solutions of acetic acid in the corresponding ionic liquid had extremely low acidity, much lower than even the acetic acid itself. This explains why, typically, this system is not catalytically active. ${ }^{39}$

From a practical viewpoint, when handling solutions of HOTf and $\mathrm{HNTf}_{2}$ in ionic liquids, there is a safety benefit as the solutions do not fume like the corresponding neat acids, and are consequentially easier to handle.

ACIDITY VS. CLUSTER STRUCTURE To aid understanding of the structure of liquid-phase clusters, the crystal structures of salts where the $[\mathrm{A}(\mathrm{HA})]^{-}$clusters were observed, were analysed. ${ }^{40}$ 
Distances between hydrogen and oxygen atoms partaking in $\mathrm{H}$-bonding in $\left[\mathrm{A}^{\cdots} \mathrm{H}-\mathrm{A}\right]^{-}$dimeric clusters were averaged for acetate clusters (8 structures), mesylate clusters (3 structures, proton detected for 2 ) and triflate clusters ( 5 structures, proton detected for 3 ). No clusters with $\left[\mathrm{NTf}_{2}\right]^{-}$anions have been deposited to date. Results of this exercise are shown in Table 3.

Table 3. Distances between hydrogen and oxygen atoms partaking in $\mathrm{H}$-bonding in $\left[\mathrm{A}^{\cdots} \mathrm{H}-\mathrm{A}\right]^{-}$dimeric clusters, based on averaged data from $\mathrm{CSD}^{40}$

\begin{tabular}{|c|c|c|c|c|}
\hline cluster & $\mathbf{O}-\mathbf{H} / \AA^{\mathrm{a}}$ & $\mathbf{H}^{\cdots} \mathbf{O} / \AA^{\mathrm{a}}$ & $\mathbf{O} \cdots \mathbf{O} / \AA$ & $\angle$ o-H...o $/^{\circ}$ \\
\hline$\left[\mathbf{A c O}^{\cdots} \mathrm{H}-\mathrm{OAc}\right]^{-}$ & $1.23 \pm 0.01$ & $1.23 \pm 0.01$ & $2.46 \pm 0.01$ & $178 \pm 3$ \\
\hline [MsO $\left.^{\cdots} \mathrm{H}-\mathrm{OMs}\right]^{-}$ & $1.03 \pm 0.10$ & $1.45 \pm 0.10$ & $2.50 \pm 0.03$ & $172 \pm 2$ \\
\hline [TfO $\left.^{\cdots}{ }^{-H}-O T f\right]^{-}$ & $0.78 \pm 0.12$ & $1.73 \pm 0.07$ & $2.49 \pm 0.05$ & $171 \pm 7$ \\
\hline
\end{tabular}

${ }^{\text {a }}$ Data averaged only for detected protons

In examining these clusters, the more symmetrical is the O-H-O unit, the stronger are the internal H-bonds, and the more stable is the cluster. Thus, binuclear acetate clusters, where the two $\mathrm{O}-\mathrm{H}$ bonds have identical length $(1.23 \pm 0.01 \AA$; very strong $\mathrm{H}$ bond), are very stable. Low acidity of the proton in $[\mathrm{OAc}(\mathrm{HOAc})]^{-}$derives directly from these strong H-bonds. In mesylate complexes, [OMs(HOMs) $]^{-}$is asymmetric $\left(r_{\mathrm{O}-\mathrm{H}}=1.03\right.$ and $r_{\mathrm{O} \ldots \mathrm{H}}=1.45 \AA$ ). HOMs is a much stronger acid, and mesylate is a poorer $\mathrm{H}$-bond acceptor, and so the acid retains more of its identity as a molecular species. This trend is continued with the [OTf(HOTf $]^{-}$cluster. Triflate is a weak base and an extremely poor $\mathrm{H}$-bond acceptor; therefore $\mathrm{O}-\mathrm{H}$ bond in [OTf(HOTf)] is very short, shorter than in water $(0.957$ $\AA$ in the gas phase), and $\mathrm{O} \ldots \mathrm{H}$ is of medium strength. Schematic structures of the three dimers are shown in Figure 5.

The AN studies indicated that there is no association of $\mathrm{HNTf}_{2}$ with anions in the $\left[\mathrm{C}_{2} \mathrm{mim}\right]\left[\mathrm{NTf}_{2}\right]-\mathrm{HNTf}_{2}$ system. This is supported by the absence of $\left[\mathrm{NTf}_{2}\left(\mathrm{HNTf}_{2}\right)\right]^{-}$clusters in the CSD database, and by studies on $\mathrm{HNTf}_{2}$ solutions in non-polar solvents. ${ }^{15}\left[\mathrm{NTf}_{2}\right]^{-}$is the poorest $\mathrm{H}$-bond acceptor studied here; in addition, there is a steric hindrance, as well as fluorinefluorine and oxygen-oxygen repulsion, hindering the formation of $\mathrm{N}-\mathrm{H}^{\cdots} \mathrm{N}$ bonds, as shown in Figure 5.

This analysis ties in the empirical basicity of the anions ${ }^{30}$ with their structural consequences and resulting acidity of their solutions.

.

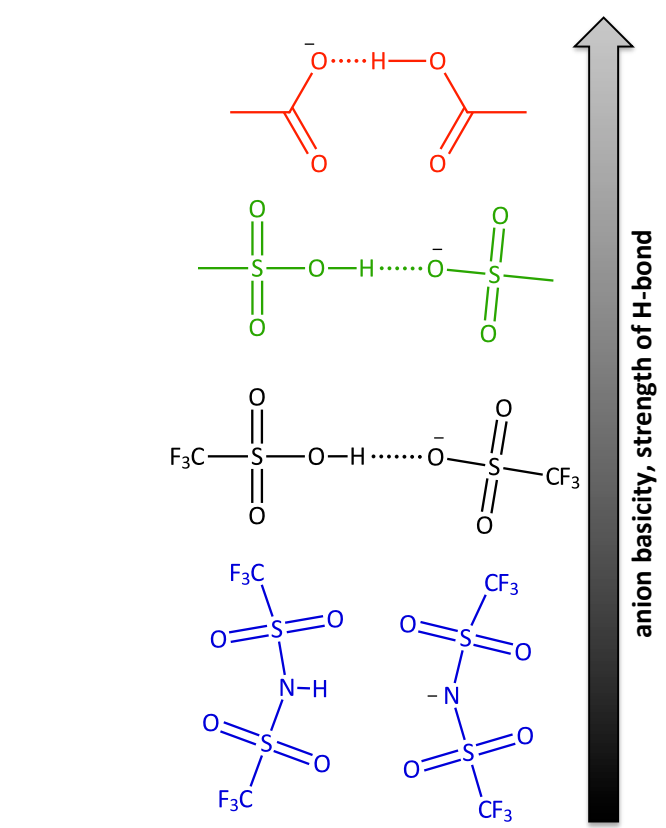

Figure 5. Proposed structures of anionic dimers, $[\mathrm{A}(\mathrm{HA})]$, in systems of a general formula $\left[\mathrm{C}_{2} \mathrm{mim}\right][\mathrm{A}]-\mathrm{HA}$, where $\mathrm{A}=\mathrm{OAc}, \mathrm{OMs}$ and OTf, compred with discrete nature of $\mathrm{HNTf} 2$ and $\left[\mathrm{NTf}_{2}\right]^{-}$in the $\left[\mathrm{C}_{2} \mathrm{mim}\right]\left[\mathrm{NTf} \mathrm{f}_{2}\right]-\mathrm{HNTf}_{2}$ system

\section{${ }^{1}$ H NMR spectroscopy}

${ }^{1} \mathrm{H}$ NMR spectra were measured for four liquid systems at ambient temperature, each over a range of $\chi_{\mathrm{HA}}$ values. As expected, chemical shifts of the acidic protons in the $\left[\mathrm{C}_{2} \mathrm{mim}\right][\mathrm{OAc}]-\mathrm{HOAc}$ system were the most sensitive to compositional changes (Figure 6), and those in the $\left[\mathrm{C}_{2} \mathrm{mim}\right]\left[\mathrm{NTf}_{2}\right]-\mathrm{HNTf}_{2}$ system was the least affected (Figure 9). The most deshielded protons were found in $\left[\mathrm{C}_{2}\right.$ mim] $[$ OTf]-HOTf system (Figure 8). Spectra for $\left[\mathrm{C}_{2} \mathrm{mim}\right][\mathrm{OMs}]-\mathrm{HOMs}$ are shown in Figure 7.

Interactions of imidazolium cations with anions in ionic liquids are well discussed elsewhere. ${ }^{34,41}$ The chemical shifts of protons in the imidazolium ring depend on the anion (downfield shift due to H-bonding) and on the concentration (upfield shift due to ring stacking). The proton in the $\mathrm{C} 2$ position is the most acidic, hence it is the most sensitive to changes in $\mathrm{H}$-bond accepting ability of the anion. The ${ }^{1} \mathrm{H}$ NMR chemical shifts for the $\mathrm{C} 2$ protons in the four systems are plotted as a function of composition, $\chi_{\mathrm{HA}}$, in Figure 10. 


\section{ARTICLE}

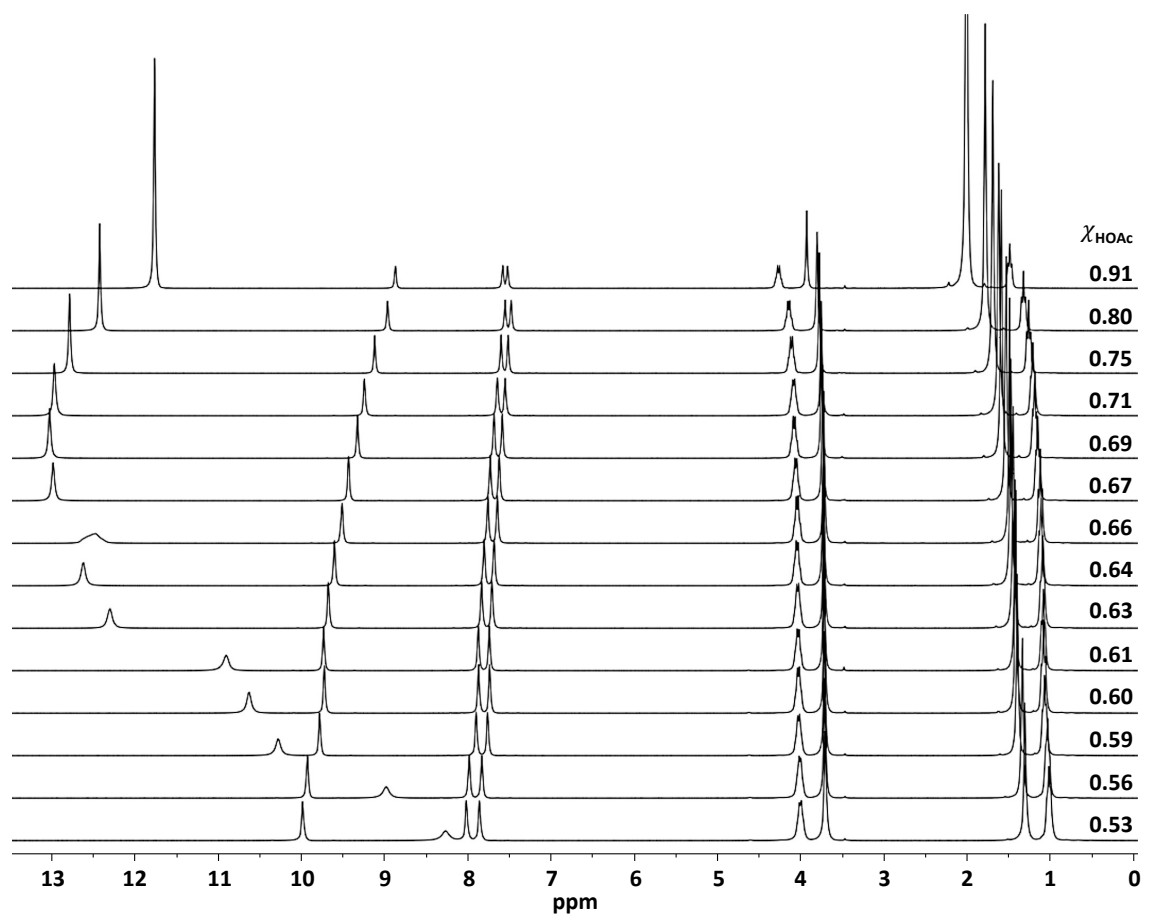

Figure 6. ${ }^{1} \mathrm{H}$ NMR spectra $\left(400.112 \mathrm{MHz}, 27{ }^{\circ} \mathrm{C}\right.$, neat, external $\mathrm{d}_{6}$-DMSO lock) of the $\left[\mathrm{C}_{2} \mathrm{mim}\right][\mathrm{OAc}]$-HOAc system; the $\chi_{\text {HOAc }}$ values are marked in the Figure.

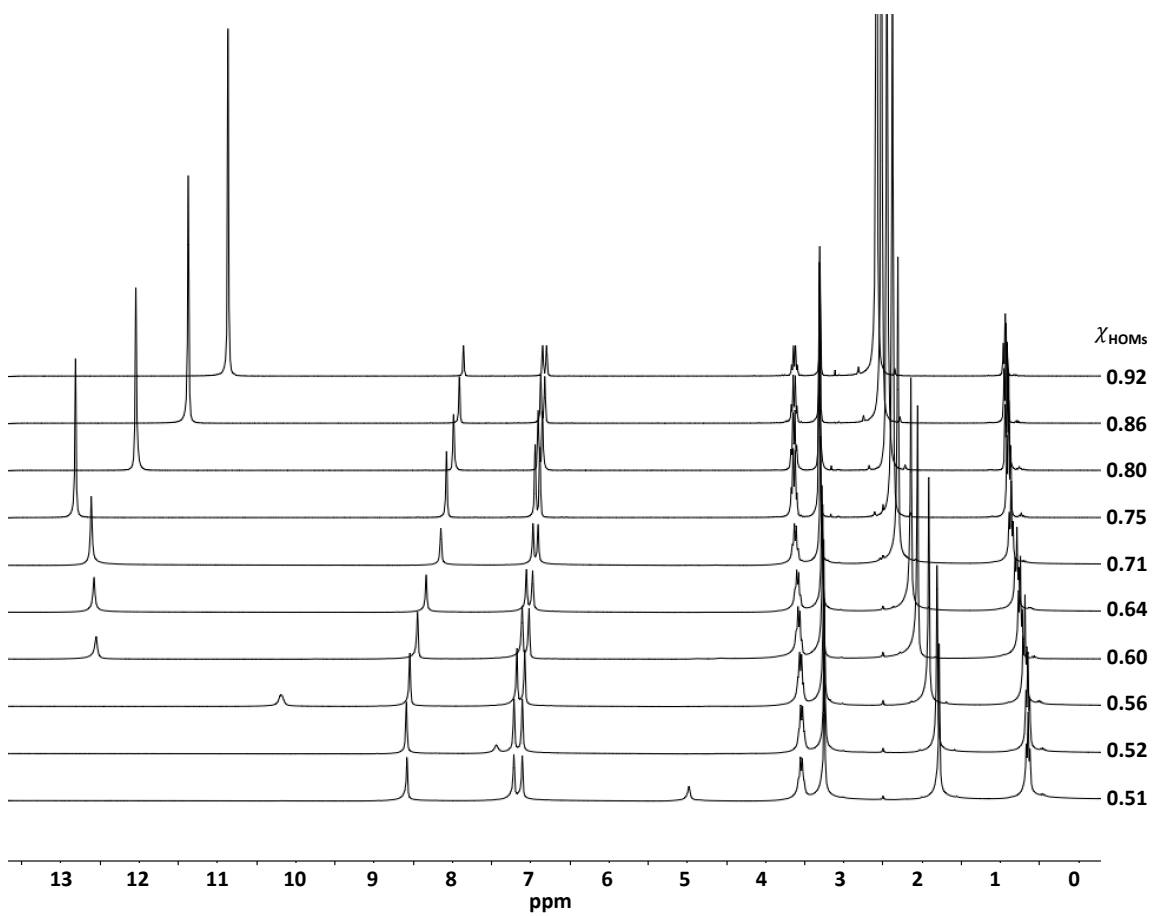

Figure 7. ${ }^{1} \mathrm{H}$ NMR spectra $\left(400.112 \mathrm{MHz}, 27^{\circ} \mathrm{C}\right.$, neat, external $\mathrm{d}_{6}$-DMSO lock) of the $\left[\mathrm{C}_{2} \mathrm{mim}\right][\mathrm{OMs}]-\mathrm{HOMs}$ system; the $\chi_{\text {HoMs }}$ values are marked in the Figure. 


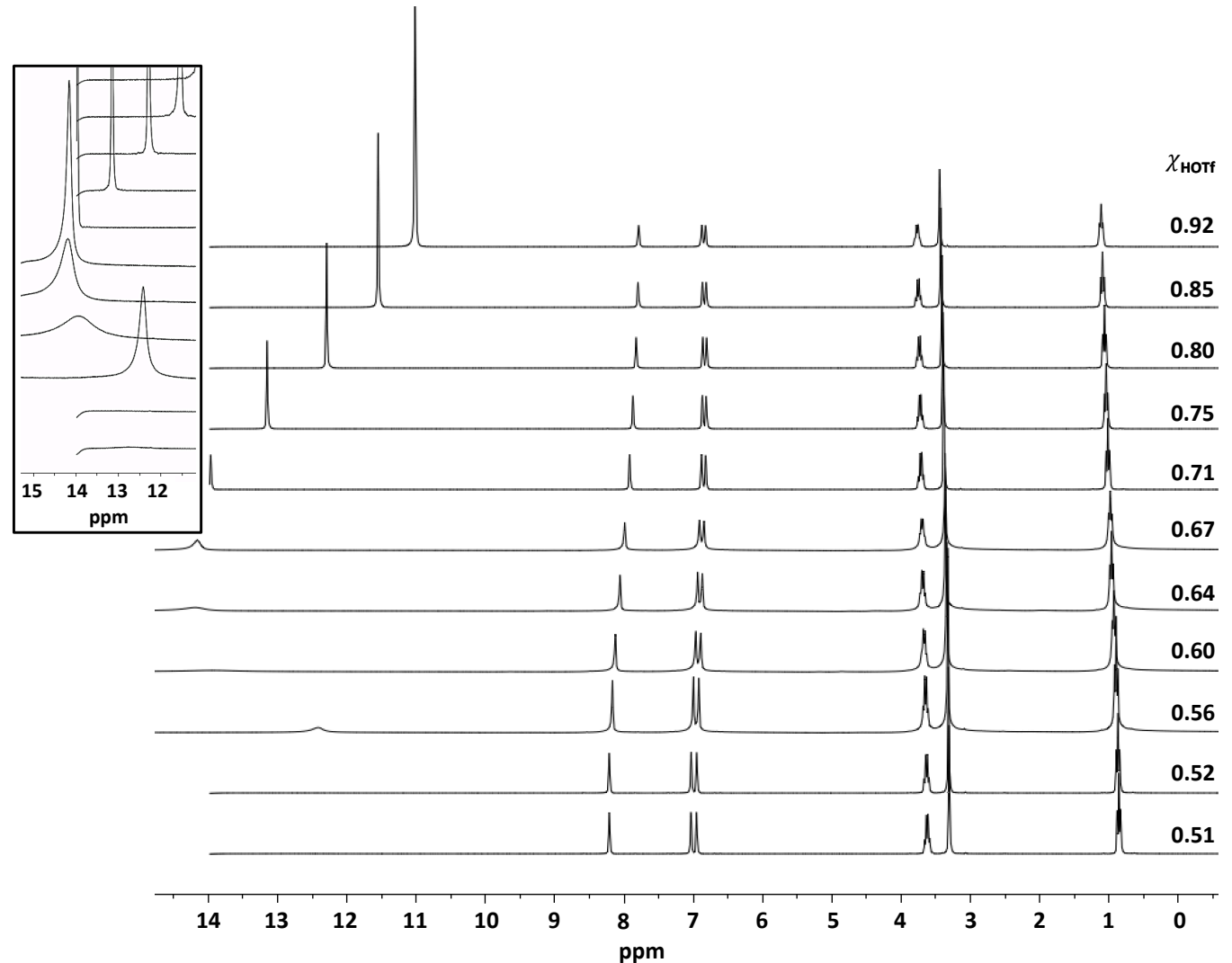

Figure 8. ${ }^{1} \mathrm{H}$ NMR spectra $\left(400.112 \mathrm{MHz}, 27{ }^{\circ} \mathrm{C}\right.$, neat, external $\mathrm{d}_{6}$-DMSO lock) of the [ $\mathrm{C}_{2}$ mim][OTf]-HOTf system; the $\chi_{\text {HOTf }}$ values are marked in the Figure. Magnification of a downfield part of a spectrum, showing low-intensity signals for compositions of lower acid content.

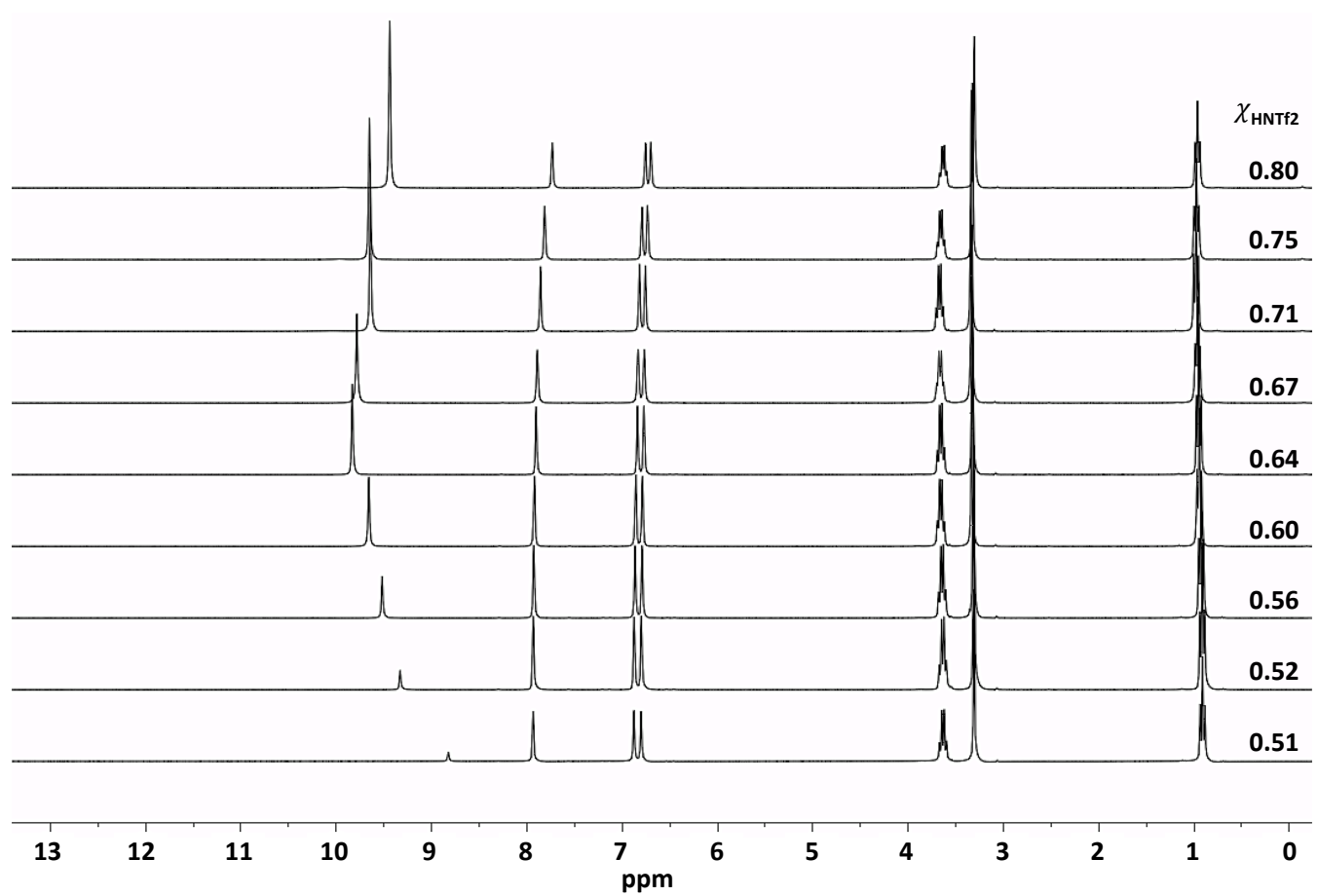

Figure $9 .{ }^{1} \mathrm{H}$ NMR spectra $\left(400.112 \mathrm{MHz}, 27^{\circ} \mathrm{C}\right.$, neat, external $\mathrm{d}_{6}$-DMSO lock) of the $\left[\mathrm{C}_{2} \mathrm{mim}\right]\left[\mathrm{NTf} \mathrm{f}_{2}\right]-\mathrm{HNTf}_{2}$ system; the $\chi_{\mathrm{NTf2}}$ are marked in the Figure. 


\section{ARTICLE}

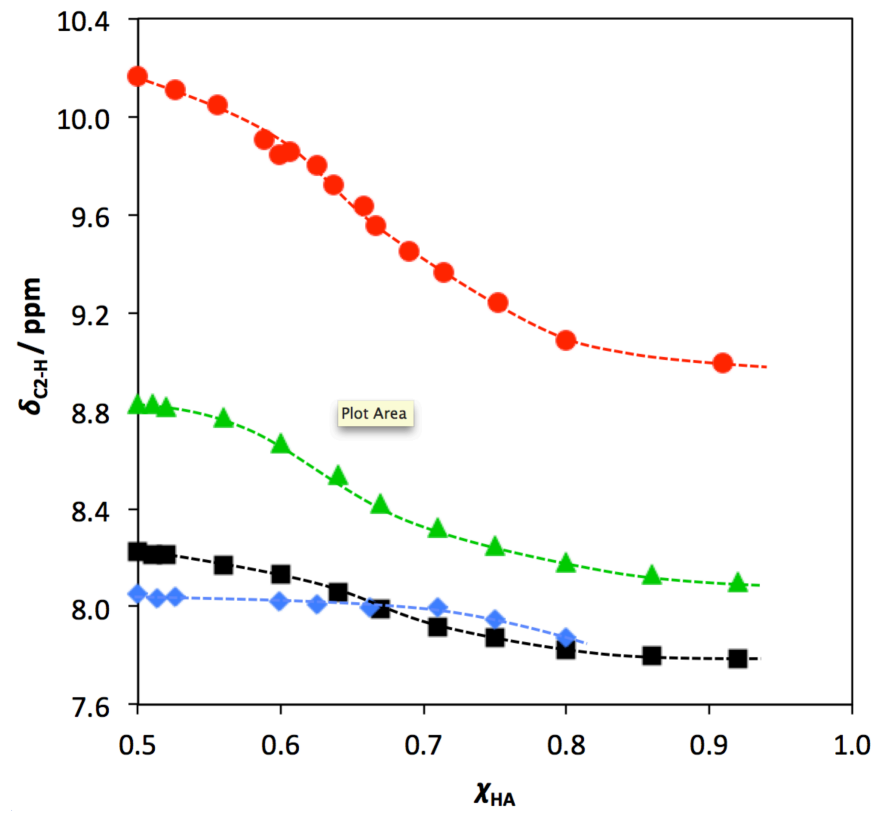

Figure 10. Changes in chemical shift of $\mathrm{C} 2-\mathrm{H}$ proton, $\delta_{\mathrm{C} 2-\mathrm{H}}$, as a function of composition, $\chi_{\mathrm{HA}}$, for four systems of a general formula $\left[\mathrm{C}_{2} \mathrm{mim}\right][\mathrm{A}]-\mathrm{HA}$, where: $A=\operatorname{OAc}(\bullet)$, OMs $(\Delta)$, OTf $(\bullet)$, or $\operatorname{NTf}_{2}(\star)$. Dashed curves are only guideline for the eye.

The most basic anions form the strongest H-bonds. Therefore, in the neat acetate ionic liquid, the $\delta_{\mathrm{C} 2-\mathrm{H}}$ signal is strongly shifted downfield (10.165 ppm), and it is found more upfield for the other ionic liquids, in the order of decreasing basicity of the anion: [OMs] $]^{-}(9.015 \mathrm{ppm}), \mathrm{OOTf}^{-}(8.370 \mathrm{ppm})$ and $\left[\mathrm{NTf}_{2}\right]^{-}(8.053 \mathrm{ppm})$. Upon addition of an acid, when $\mathrm{H}$-bonded clusters are formed, the strength of the cation-anion interactions decreases in favour of acid-anion interactions (Figure 11).

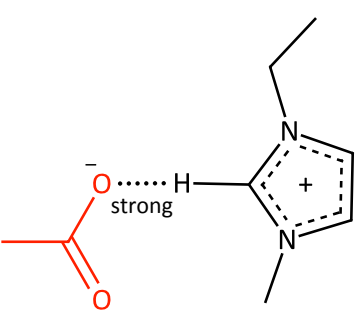

$$
\chi_{\mathrm{HA}}=\mathbf{0 . 5 0}
$$

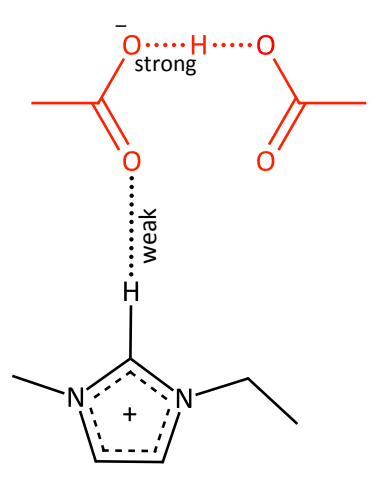

$\chi_{\mathrm{HA}}=\mathbf{0 . 6 7}$
Figure 11. $\mathrm{H}$-bonding in a neat ionic liquid $\left(\chi_{\mathrm{HA}}=0.50\right)$ and in an equimolar mixture of ionic liquid and acid, sharing the same conjugate base $\left(\chi_{\mathrm{HA}}=0.67\right)$, exemplified for the $\left[\mathrm{C}_{2} \mathrm{mim}\right][\mathrm{OAc}]-\mathrm{HAc}$ system.
This is true for acetate, mesylate and triflate systems, which all follow the same trend, reflecting the formation of $\left[\mathrm{A}(\mathrm{HA})_{2}\right]^{-}$ clusters, and then further upfield shift of the $\delta_{\mathrm{C} 2-\mathrm{H}}$ signal as oligomeric $\left[\mathrm{A}(\mathrm{HA})_{x}\right]^{-}$clusters are formed. In other words, complex $\left[\mathrm{A}(\mathrm{HA})_{x}\right]^{-}$anions are weaker bases than corresponding $[\mathrm{A}]^{-}$, due to charge distribution of a single negative charge over a greater number of electronegative centres. The $\left[\mathrm{NTf}_{2}\right]^{-}$ anion is essentially unable to associate with $\mathrm{HNTf}_{2}$, so the $\delta_{\mathrm{C} 2-\mathrm{H}}$ signal is constant up to $\chi_{\mathrm{NTf} 2} \cong 0.70$ (two moles of acid per one mol of ionic liquid). Above this concentration, it is possible that the acid and anions begin to agglomerate via weak $\mathrm{N}-\mathrm{H}$... O bonding (Figure 3), which leads to further weakening of cationanion interaction.

For both triflate and bistriflamide systems, at high acid concentrations, the $\delta_{\mathrm{C} 2-\mathrm{H}}$ signals achieve identical values, which may be assumed to be the chemical shift for an effectively non $\mathrm{H}$-bonded $\mathrm{C} 2$ proton in a neat $\left[\mathrm{C}_{2} \mathrm{mim}\right]^{+}$ionic liquid.

${ }^{1} \mathrm{H}$ NMR chemical shifts for the acidic protons in $\left[\mathrm{A}(\mathrm{HA})_{x}\right]^{-}$ complexes, $\delta_{\mathrm{A} \ldots \mathrm{H} \ldots \mathrm{A}}$, are plotted as a function of composition, $\chi_{\mathrm{HA}}$, in Figure 12.

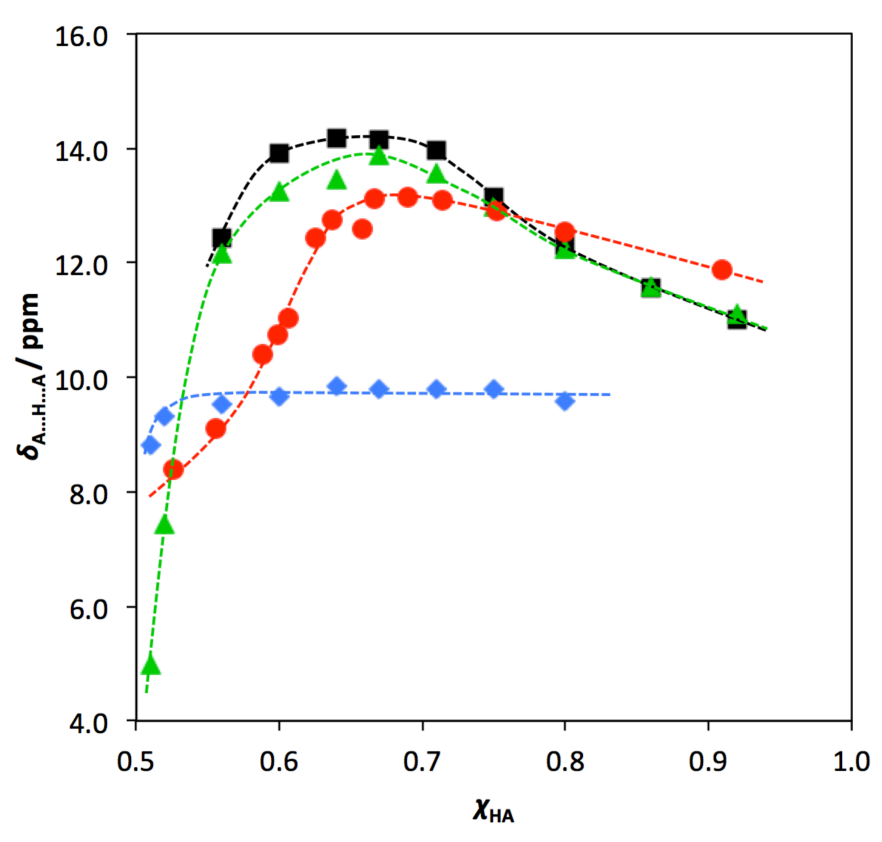

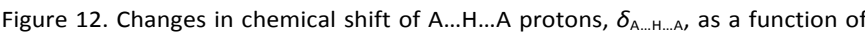
composition, $\chi_{\mathrm{HA}}$, for four systems of a general formula $\left[\mathrm{C}_{2} \mathrm{mim}\right][\mathrm{A}]-\mathrm{HA}$, where: $\mathrm{A}=\operatorname{OAc}(\bullet)$, OMs $(\Delta)$, OTf $(\boldsymbol{\bullet})$, or $\mathrm{NTf}_{2}(\bullet)$. Dashed curves are only guideline for the eye.

As the composition changes, the observed signal is an average from several acidic proton signals, derived from $\mathrm{H}$-bonded clusters in dynamic equilibria (Eqn 5). This has been demonstrated experimentally in low-temperature NMR studies on the pyridine-acetic acid system by Golubev et al.,${ }^{38}$ where signals corresponding to $[\mathrm{OAc}(\mathrm{HOAc})]^{-},\left[\mathrm{OAc}(\mathrm{HOAc})_{2}\right]^{-}$, and to acid dimers $\left[(\mathrm{HOAc})_{2}\right]$, were observed. 
Analogous behaviour was observed for acetate, mesylate and triflate systems. With increasing acid content, the $\delta_{\mathrm{A}} \ldots \mathrm{H} \ldots \mathrm{A}$ signals shift downfield, to plateau around $\chi_{\mathrm{HA}}=0.67$. This corresponds to a maximum in the concentration of $[\mathrm{A}(\mathrm{HA})]^{-}$. It is known that, amongst $\mathrm{H}$-bonded complexes, [A(HA)] dimers have the strongest $\mathrm{H}^{\cdots} \mathrm{O}$, therefore the weakest $\mathrm{O}-\mathrm{H}$ bonds, and in consequence such protons are the most deshielded. ${ }^{38}$ Moving towards higher $\chi_{\mathrm{HA}}$ values, $\delta_{\mathrm{A} \ldots \mathrm{H} \ldots \mathrm{A}}$ signals shift upfield. The gradual decrease in $\delta_{\mathrm{A}} \ldots \mathrm{H} \ldots \mathrm{A}$ in the acetate system corresponds to the formation of discrete trinuclear clusters. Further addition of acid leads to a solution of ionic liquid in acid. Although the existence of higher-order clusters was postulated also in triflate systems, ${ }^{15}$ data in Figure 12 show no evidence for larger clusters in either mesylate or triflate system. It appears that, as the acid content increases beyond $\chi_{\mathrm{HA}}=0.67$, the equilibrium shown in Eqn 5 shifts to the left, liberating free acid. This behaviour lies on the opposite spectrum to known behaviour of [cation]F-HF system, where polynuclear clusters were recorded. ${ }^{42}$

The $\delta_{\mathrm{A} \ldots \mathrm{H} \ldots \mathrm{A}}$ values recorded for the $\left[\mathrm{C}_{2} \mathrm{mim}\right]\left[\mathrm{NTf}_{2}\right]-\mathrm{HNTf}_{2}$ system $\left(0.51<\chi_{\mathrm{HA}} \leq 0.80\right)$ remain constant, and are shifted relatively far upfield when compared to the other studied systems. This corresponds to molecular $\mathrm{HNTf}_{2}$ solvated in the ionic liquid.

It is extremely noteworthy that, as clearly evidenced by presented data, the chemical shift of the acidic proton does not correspond to its actual ability to protonate a base.

\section{Conclusions}

It has been demonstrated that Acceptor Number is a valid and reliable measure of the Brønsted acidity in ionic liquids, from very weak to very strong acids. A library of ionic liquid-acid solutions, characterised by a wide spectrum of acidity, has been developed.

Brønsted acids dissolved in ionic liquids typically form anionic $\mathrm{H}$-bonded clusters, $\left[\mathrm{A}(\mathrm{HA})_{x}\right]^{-}$. AN measurements are sensitive to the structure of the liquids, and reflect how acidity changes with changing liquid structure. The value of $x$ depends on the basicity of $\mathrm{A}^{-}$in the system; for acetate $x=1$ or 2 , for mesylate or triflate $x=1$, and for bistriflamide $x=0$ (the clusters do not form).

Unlike acids with stronger conjugate bases, $\mathrm{HNTf}_{2}$ does aggregate with the anions in $\left[\mathrm{NTf}_{2}\right]^{-}$-based ionic liquids, but is solubilised in a molecular form. At low concentrations, $\left[\mathrm{C}_{2} \mathrm{mim}\right]\left[\mathrm{NTf}_{2}\right]-\mathrm{HNTf}_{2}$ system is more acidic than $\left[\mathrm{C}_{2}\right.$ mim][OTf]-HOTf system, but at very high HOTf concentration the order is reversed (see Figure 4).

${ }^{1} \mathrm{H}$ NMR chemical shifts of the acidic protons, $\delta_{\mathrm{A} \ldots \mathrm{H} \ldots \mathrm{A}}$, do not correspond to the strength of Brønsted acidity in the system, but rather inform on the relative strength of $\mathrm{H}$-bonding between acid and anions in the anionic clusters.

In summary, a simple way to manipulate and quantify Brønsted acidity of acid-ionic liquid mixtures was demonstrated, and measured AN values were related to the liquid speciation, which in turn provided structural and quantitative underpin for the selection of Brønsted acidic ionic liquid system for a catalytic application.

\section{Acknowledgements}

The authors acknowledge QUILL and its Industrial Advisory Board, as well as the EPSRC (Portfolio Partnership Scheme, Grant EP/D029538/1), for support. Dr P. Nockemann is acknowledged for useful discussion about crystallography, and Mr R. W. Murphy for help with NMR studies.

\section{Notes and references}

${ }^{a}$ QUILL, The Queen's University of Belfast, Belfast, BT9 5AG, United Kingdom, E-mail: m.swadzba.kwasny@qub.ac.uk

${ }^{b}$ CERTECH asbl, Rue Jules Bordet, Zone Industrielle C, B-7180 Seneffe, Belgium

$\dagger$ Footnotes should appear here. These might include comments relevant to but not central to the matter under discussion, limited experimental and spectral data, and crystallographic data.

Electronic Supplementary Information (ESI) available: [details of any supplementary information available should be included here]. See DOI: $10.1039 / \mathrm{b} 000000 \mathrm{x} /$

1 (a) K. Bica and R. D. Rogers, Chem. Commun., 2010, 46, 1215; (b) J. Stoimenovski, D. R. MacFarlane, K. Bica and R. D. Rogers, Pharm. Res., 2010, 27, 521; (c) J. Stoimenovski, P. M. Dean, E. I. Izgorodina and D. R. MacFarlane, Faraday Discuss., 2011, 154, 335.

2 L. Myles, R. Gore, M. Špulák, N. Gathergood and S. J. Connon, Green Chem, 2010, 12, 1157.

3 E. Margaretta, C. Olmeda, and L. Yu, J. Appl. Polym. Sci., 2012, 127, 2453.

4 (a) K. Sasaki, H. Nagai, S. Matsumura and K. Toshima, Tetrahedron Lett., 2003, 44, 5605; (b) M. P. Atkins, M. J. Earle, K. R. Seddon, M. Swadźba-Kwaśny and L. Vanoye, Chem. Commun., 2010, 46, 1745.

5 K. Matuszek, A. Chrobok, F. Coleman, K. R. Seddon, and M. Swadzba-Kwasny, Green Chem, 2014, DOI: 10.1039/c4gc00415a.

6 M. Yoshizawa, W. Xu and C. A. Angell, J. Am. Chem. Soc., 2003, 125, 15411 .

7 T. A. Zawodzinski and R. A. Osteryoung, Inorg. Chem., 1988, 27, 4383.

8 J. Campbell and K. Johnson, Inorg. Chem., 1993, 32, 3809.

9 G. Driver and K. E. Johnson, Green Chem., 2003, 5, 163.

10 C. M. Burba, N. M. Rocher and R. Frech, J. Phys. Chem. B, 2009, 113, 11453.

11 G. A. Olah, T. Mathew, A. Goeppert, B. Török, I. Bucsi, X.-Y. Li, Q. Wang, E. R. Marinez, P. Batamack, R. Aniszfeld and G. K. S. Prakash, J. Am. Chem. Soc., 2005, 127, 5964.

12 F. Kohler, H. Atrops, H. Kalali, E. Liebermann, E. Wilhelm, F. Ratkovics and T. Salamon, J. Phys. Chem., 1981, 85, 2520.

13 K. M. Johansson, E. I. Izgorodina, M. Forsyth, D. R. MacFarlane and K. R. Seddon, Phys. Chem. Chem. Phys., 2008, 10, 2972.

14 R. D. Gillard and R. Ugo, J. Chem. Soc., A, 1966, 549.

15 E. S. Stoyanov, K.-C. Kim, and C. A. Reed, J. Phys. Chem. A, 2004, 108, 9310.

16 T. Ramnial, S. A. Taylor, M. L. Bender, B. Gorodetsky, P. T. K. Lee, D. A. Dickie, B. M. McCollum, C. C. Pye, C. J. Walsby and J. A. C. Clyburne, J. Org. Chem., 2008, 73, 801.

17 J. Foropoulos Jr and D. D. DesMarteau, Inorg Chem, 1984, 23, 3720.

18 (a) A. Haas, C. Klare, P. Betz, J. Bruckmann, C. Krüger, Y.-H. Tsay and F. Aubke, Inorg. Chem., 1996, 35, 1918; (b) Z. Zak, A. Ruzicka and C. Michot, Z. Kristallogr., 1998, 213, 217. 
19 M. Herstedt, M. Smirnov, P. Johansson, M. Chami, J. Grondin, L. Servant and J. C. Lassegues, J. Raman Spectrosc., 2005, 36, 762.

20 K. Fujii, Y. Soejima, Y. Kyoshoin, S. Fukuda, R. Kanzaki, Y. Umebayashi, T. Yamaguchi, S.-I. Ishiguro and T. Takamuku, J. Phys. Chem. B, 2008, 112, 4329

21 I. A. Koppel, R. W. Taft, F. Anvia, S.-Z. Zhu, L.-Q. Hu, K.-S. Sung, D. D. DesMarteau, L. M. Yagupolskii and Y. L. Yagupolskii, J. Am. Chem. Soc., 1994, 116, 3047.

22 I. A. Koppel, R. W. Taft, F. Anvia, S.-Z. Zhu, L.-Q. Hu, K.-S. Sung, D. D. DesMarteau, L. M. Yagupolskii and Y. L. Yagupolskii, J. Am. Chem. Soc., 1994, 116, 3047.

23 B. C. Thompson, O. Winther-Jensen, B. Winther-Jensen and D. R. MacFarlane, Anal Chem, 2013, 85, 3521.

24 K. E. Johnson, R. M. Pagni and J. Bartmess, Monatsh. Chem., 2007, 138, 1077.

25 L. M. Mihichuk, G. W. Driver and K. E. Johnson, ChemPhysChem, 2011, 12, 1622.

26 T. Robert, L. Magna, H. Olivier-Bourbigou and B. Gilbert, $J$ Electrochem Soc, 2009, 156, F115.

27 J. Gräsvik, J. P. Hallett, T. Q. To, and T. Welton, Chem. Commun., 2014, doi: $10.1039 / \mathrm{c} 4 \mathrm{cc} 02816 \mathrm{c}$.

28 V. Gutmann, The Donor-Acceptor Approach to Molecular Interactions, Plenum Press, New York, 1978.

29 (a) T. A. Zawodzinski Jr and R. A. Osteryoung, Inorg Chem, 1989, 28, 1710; (b) J. Estager, A. A. Oliferenko, K. R. Seddon and M. Swadźba-Kwaśny, Dalton Trans., 2010, 39, 11375; (c) J. Estager, P. Nockemann, K. R. Seddon, M. Swadźba-Kwaśny and S. Tyrrell, Inorg. Chem., 2011, 50, 5258; (d) M. Currie, J. Estager, P. Licence, S. Men, P. Nockemann, K. R. Seddon, M. Swadźba-Kwaśny and C. Terrade, Inorg. Chem., 2013, 52, 1710.

30 (a) M. Schmeisser, P. Illner, R. Puchta, A. Zahl and R. van Eldik, Chem. Eur. J., 2012, 18, 10969; (b) M. Holzweber, R. Lungwitz, D. Doerfler, S. Spange, M. Koel, H. Hutter and W. Linert, Chem. Eur. J., 2012, 19, 288.V. Gutmann, The Donor-Acceptor Approach to Molecular Interactions, Plenum Press, New York, 1978.

31 L. Magna, J. Bildé, H. Olivier-Bourbigou, T. Robert and B. Gilbert, Oil Gas Sci. Technol., 2009, 64, 669.

32 (a) J. Estager, A. A. Oliferenko, K. R. Seddon and M. SwadźbaKwaśny, Dalton Trans, 2010, 39, 11375; (b) J. Estager, P. Nockemann, K. R. Seddon, M. Swadźba-Kwaśny and S. Tyrrell, Inorg Chem, 2011, 50, 5258; (c) M. Currie, J. Estager, P. Licence, S. Men, P. Nockemann, K. R. Seddon, M. Swadźba-Kwaśny and C. Terrade, Inorg Chem, 2013, 52, 1710.
33 L. Conte, G. Gambaretto, G. Caporiccio, F. Alessandrini and S. Passerini, J Fluorine Chem, 2004, 125, 243.

34 P. Bonhôte, A.-P. Dias, N. Papageorgiou, Michel Armand, K. Kalyanasundaram and M. Grätzel, Inorg Chem, 1996, 35, 1168.

35 M. Blesic, M. Swadźba-Kwaśny, J. D. Holbrey, J. N. Canongia Lopes, K. R. Seddon, and L. P. N. Rebelo, Phys Chem Chem Phys, 2009, 11, 4260.

36 J. L. Ferguson, J. D. Holbrey, S. Ng, N. V. Plechkova, K. R. Seddon, A. A. Tomaszowska and D. F. Wassell, Pure Appl. Chem., 2012, 84, 723.

37 A. M. Magill, K. J. Cavell and B. F. Yates, J. Am. Chem. Soc., 2004, 126, 8717 .

38 N. S. Golubev, S. N. Smirnov, V. A. Gindin, G. S. Denisov, H. Benedict and H.-H. Limbach, J. Am. Chem. Soc., 1994, 116, 12055.

39 C. Chiappe and S. Rajamani, Eur. J. Org. Chem., 2011, 2011, 5517.

40 F. H. Allen, Acta Cryst. B, 2002, 58, 388.

41 A. Elaiwi, P. B. Hitchcock, K. R. Seddon, N. Srinivasan, Y.-M. Tan, T. Welton and J. A. Zora, J. Chem. Soc., Dalton Trans., 1995, 3467.

42 G. A. Olah, T. Mathew, A. Goeppert, B. Török, I. Bucsi, X.-Y. Li, Q. Wang, E. R. Marinez, P. Batamack, R. Aniszfeld and G. K. S. Prakash, J. Am. Chem. Soc., 2005, 127, 5969. 